Es pn ento ge se de anyah k imputaci. de le fennl de 3 ngs, gor sindux ofre les mier posililide pu ut bleen la calile del thinpeco as sureleci- (a myldh, le creacie munta! de puive, ia my impstente ap atzi- del ci-ic argester a la sepel mitd cl sish $x \times$, arlanch co$\rightarrow$ ue de a insuze my mtabla de li- re- vitur, y

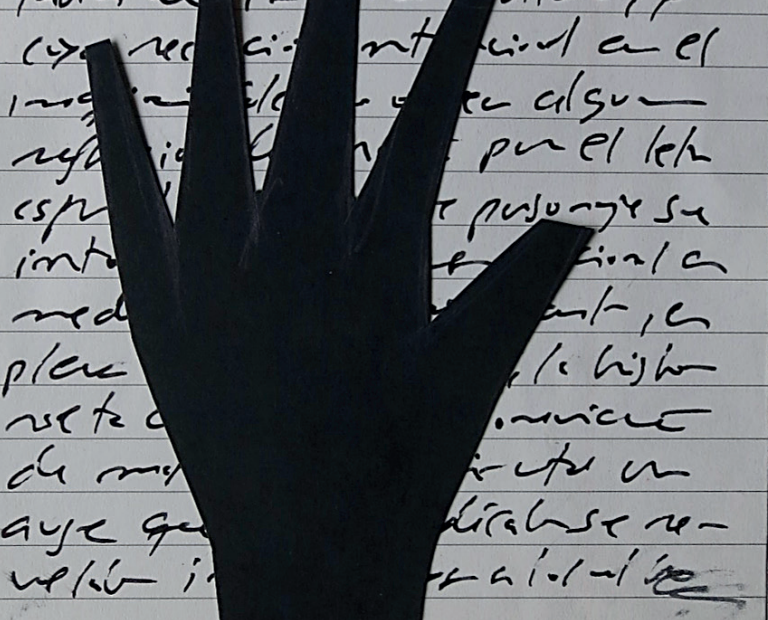


AUTOR: Javier Cabo 


\title{
A voltas coa posverdade ${ }^{1}$
}

\author{
Darío Villanueva Prieto \\ [Recibido, 20 marzo 2019; aceptado, 6 xuño 2019] \\ http://dx.doi.org/10.15304/bgl.54.5904
}

RESUMO A posverdade, entendida como toda información ou aseveración que non se basea en feitos obxectivos, senón que apela ás emocións, crenzas ou desexos do público, é o concepto xurdido da actual posmodernidade (ou transmodernidade para algúns autores) que se remonta ao último terzo do século XX. Non obstante, o presente artigo defende a antigüidade do concepto e bota a vista atrás para realizar unha viaxe por varios antecedentes relacionados con distintos ámbitos como o literario, político ou os medios de comunicación. Deste xeito, faise posíbel chamar a atención sobre a problemática da posverdade na contemporaneidade e a incidencia dos avances da comunicación audiovisual e da realidade virtual que complican aínda máis o desenvolvemento da capacidade do ser humano de discernir entre realidade e ficción, entre verdade e mentira.

PALABRAS CHAVE: comunicación audiovisual; ficción; posmodernidade; posverdade; realidade.

ABSTRACT The post-truth, defined as any information or assertion what isn't based in objectives facts, but appealing to emotions, beliefs or public wants, is the concept resulting from the current postmodernity (or transmodernity according to some authors) which dates back to the last quarter of the twentieth century. Nevertheless, this article defends the antiquity of the concept and looking back to the past experiences a tour through several antecedent related to different scopes such as literature, policy or mass media. In this way it is possible to draw attention to the problem in the contemporaneity and the impact of advances in audiovisual communication and the virtual reality which make even more complicated the development of humankind's capacity for discerning between reality and fiction, between truth and lie.

KEYWORDS: audiovisual communication; fiction; postmodernity; post-truth; reality.

1 Este artigo deslígase da conferencia presentada no Centro Ramón Piñeiro para a Investigación en Humanidades en marzo do 2018 por mor da celebración dos 25 anos en activo da institución. 


\section{Introdución}

Dende o último terzo do século XX tomou forza a definición da nosa época baixo o rótulo da posmodernidade. Pero como o ritmo dos cambios é agora máis frenético ca nunca antes, algúns filósofos levan anos advertíndonos que xa estamos en plena transmodernidade, non caracterizada polo esgotamento dos grandes relatos (isto é, as ideoloxías), senón pola vitoria dun deles, até certo punto novo: a globalización.

Neste contexto xorde un novo concepto, interesante á vez que preocupante: a posverdade. A forza do seu impacto sobre a conciencia dos políticos e intelectuais, e mesmo no propio imaxinario colectivo, queda patente logo de que o prestixioso dicionario inglés de Oxford a distinguise en 2016 co título honorífico de palabra do ano (en 2013 fora seleccionada selfie, en 2014 vapear e en 2015 emoji). Segundo o antedito manual, post-truth é un adxectivo que se refire a circunstancias que denotan que os feitos obxectivos inflúen menos na formación da opinión pública que os chamamentos á emoción e ás crenzas persoais.

Mais considero que esta creación léxica e conceptual non é tan recente, senón que vai implícita na novela distópica de George Orwell titulada Nineteen Eighty-Four e publicada en 1949, lectura amplamente recomendada. A distopía é a representación ficticia dunha sociedade futura de características negativas causantes da alienación humana. Orwell quedou curto ao pór á fronte unha data tan temperá, 1984. O mundo que el describe está a facerse certo no actual século XXI. Por exemplo, o protagonista da novela, Winston Smith, traballa nun Ministerio da Verdade, cuxas tres consignas fundamentais son: "A guerra é a paz", "A liberdade é a escravitude" e "A ignorancia é a forza".

En 2004, o xornalista estadounidense Eric Alterman cualificou como "presidencia da posverdade" a de George W. Bush. E sempre nesta clave política, reavívase a vixencia da posverdade grazas a moitos dos argumentos dos políticos ingleses partidarios do chamado Brexit, e, sobre todo, dos tweets e arengas de Donald Trump ao longo da súa campaña presidencial, e mesmo despois. The New York Times acaba de revelar que dos tweets que Trump publicou dende a súa entrada na Casa Branca, o 20 de xaneiro do ano pasado, en noventa e nove casos propagaba falsidades; por exemplo, que fose el o home 
que máis veces ocupara a portada da revista Time. Mente ao dicir que fora en 14 ou 15 ocasións, cando foron exactamente once. O presidente Nixon chegou a aparecer nin máis nin menos que en 55 portadas. Nun contexto máis próximo estaría o "procés catalán", que daría moito que falar á mantenta da posverdade.

Moi famoso se fixo, neste sentido, o argumento dunha asesora da Casa Branca, que desautorizaba as críticas xeneralizadas provocando a declaración do portavoz do Presidente no sentido de que a toma de posesión de Trump fora a máis concorrida da historia. A asesora Conway aduciu que, en contra das fotografías, vídeos e crónicas, por exemplo, de cando Barak Obama accedeu á primeira maxistratura do seu país en olor de multitudes, o equipo de comunicación de Donald Trump manexaba "feitos alternativos". Alternativos á verdade factual, enténdese. Verdadeiras fake newws, noticias falsas que inevitablemente nos fan lembrar a aquel xenio malvado da comunicación que foi o filólogo Joseph Goebbels, ministro de propaganda de Hitler, para quen o asunto era moi simple: unha mentira repetida mil veces convértese en verdade.

Afortunadamente, a post-truth inglesa atopou sen maior problema unha tradución ao español impecable, pero sen guión no medio: posverdade. Nas bases de datos da Real Academia Española aparece con testemuñas que se remontan á publicación do 2003 de Luís Verdú, onde falaba de "la era de la posverdad". A palabra apareceu a finais do ano pasado como neoloxismo na primeira actualización do noso Diccionario de la lengua española, ofrecido gratuitamente na rede, que en marzo do 2018 tivo oitenta e un millóns de consultas. Á falta dunha definición xa pechada, todo indica que se describirá como toda información ou aseveración que non se asenta en feitos obxectivos, senón que apela ás emocións, crenzas ou desexos do público.

Resultará un tanto benévola esta definición? Probablemente si, se a comparamos coa que o escritor Julio Llamazares formulou ao final dunha das súas columnas no diario El País (22 de abril de 2017): "La posverdad no es una forma de verdad, es la mentira de toda la vida".

O propósito deste artigo é mostrar algúns antecedentes da posverdade posmoderna ou transmoderna, que suscita máis preocupación que nunca debido aos avances da comunicación audiovisual dixitalizada e a invención da realidade virtual. 


\section{Algúns antecedentes da posverdade na posmodernidade}

Teña ou non que ver cun cambio climático que se cerne sobre nós como unha ameaza apocalíptica, na primavera e verán do ano 2017 sucedéronse varias xornadas de calores caniculares e varias zonas do globo sufriron grandes catástrofes naturais.

Hai anos aparecía na prensa unha información que vén ao caso. Unha lei chinesa, vixente entón, daba venia aos traballadores para non comparecer no traballo se a temperatura ambiente superaba os corenta graos centígrados. Dados os reiterados incrementos térmicos que xa entón se viñan atribuíndo ao chamado "efecto invernadoiro", aquela filantrópica disposición laboral comezaba a ameazar a posíbel viabilidade do "milagre chinés", razón pola cal as autoridades, responsablemente, decidiran que os termómetros expostos ao público, e os datos oficiais referentes á temperatura, reflectisen de oficio dez graos menos de calor. A lei era a lei, e continuábase xustificando a sensibilidade sociolaboral do réxime, sen que se producisen, porén, efectos secundarios indesexables ou danos colaterais por culpa da teima irredutíbel da realidade térmica.

Nos antípodas, se non exactamente xeográficos si polo menos ideolóxicos da China posmaoísta, paréceme interesante reparar na personalidade do expresidente norteamericano Ronald Reagan, que ocupou a Casa Branca entre 1981 e 1989. En 1999 publicouse, con certo escándalo, unha nova biografía súa, titulada Ducht (o alcume xuvenil de Reagan), escrita por Edmund Morris, que xa gañara un Pulitzer con outra biografía, a de Theodor Roosevelt, titulada The Rise of Theodore Roosevelt (1979).

No seu libro, Morris revela que a famosa "Iniciativa de Defensa Estratéxica" do ex-presidente norteamericano, que os medios de comunicación enseguida denominaron "A Guerra das Galaxias", estivo baseada en $A$ princess of Mars (1917), un dos libros de ficción científica de Edgard Rice Burroughs, a quen Reagan admiraba.

Nada de novo hai naquela revelación do biógrafo Morris, que nos fai ratificar os asombrosos episodios contados por Lou Cannon na obra President Reagan. The Role of a Lifetime (1991), aparecida a principios dos noventa do século pasado. Ao longo das súas campañas electorais de 1976 e 1980, Rea- 
gan, coa habilidade retórica que o caracterizaba, incluída unha eficaz actuación (actio) de vello actor de Hollywood, repetiu varias veces nos seus discursos un relato que fixo tamén o 12 de decembro de 1983 ante a convención anual da "Congressional Medal of Honor Society" celebrada en Nova York.

Para exaltar o sentido patriótico do seu auditorio, de antemán entregado, o que constituíu un dos eixos centrais da súa política presidencial, sumamente interesada en vencer o que Noam Chomsky denominaba "a síndrome de Vietnam”, resultado da derrota humillante naquela guerra, Reagan narrou un emocionante caso de heroísmo. Un bombardeiro B-17, en misión sobre Alemaña durante a Segunda Guerra Mundial, foi alcanzado polos antiaéreos, co resultado de que o artilleiro da torreta quedase ferido sen que os seus compañeiros de tripulación puidesen retiralo da súa posición. Ao cruzar a canle, o avión empezou a perder altura e o comandante deu orde de saltar. O mozo ferido, véndose condenado a estrelarse contra o mar, comezou a chorar e entón o comandante sentou xunto a el, colleuno da man e díxolle: "Never mind, son, we"ll ride it down together" (tranquilo, fillo, afundirémonos xuntos). Reagan, no seu mitin, mencionou textualmente esta frase, e engadiu que o heroe recibira postumamente a "Congressional Medal of Honor".

Pero velaquí que un xornalista do New York Daily News, Lars-Erik Nelson, tomouse a molestia de consultar os rexistros da citada condecoración, que se concedeu 434 veces durante a segunda guerra mundial, e non atopou nada referente ao caso tan ponderado por Reagan. E cando comentou este sorprendente feito na súa columna xornalística, un dos seus lectores escribiulle que o episodio lembraba unha escena da película de 1944 Wings and a prayer, dirixida por Henry Hathaway e protagonizada por Dana Andrews. Alí o piloto dun avión da Navy encargado de tirar torpedos no Pacífico Sur decide heroicamente acompañar até o final ao seu operador de radio ferido dicíndolle: "We"ll take this ride together" (faremos este camiño xuntos), frase que quedou prendida na memoria do mozo Reagan. Cando Nelson levou o asunto até o gabinete da Casa Branca atopouse cunha bizarra resposta do portavoz Larry Speakes: "If you tell the same story five times, it's true" ("Se contas unha mesma historia cinco veces, pasa a ser verdadeira”); argumento semellante ao de Goebbels ou ao que se lle atribúe a Bertrand Russell cando afirmaba que os lectores de xornal adoitan confundir a verdade co corpo de letra 12 . 
Demos agora outro salto temporal, de dous séculos cara a adiante, para reencontrarnos con Ronald Reagan, a quen, á marxe de calquera valoración política, considero unha das figuras semioticamente máis interesante da posmodernidade. Como as súas biografías documentan, o que logo sería por dúas veces Presidente dos Estados Unidos fíxose un ávido consumidor de ficción científica durante a súa etapa de Hollywood, época na que estivo especialmente interesado nun dos temas favoritos do xénero: a invasión do noso globo por extraterrestres, o que reclamaba unha unión de todos os terrícolas para defenderse deixando á parte as minucias das nosas diferenzas de raza, relixión e ideoloxía.

Pois ben, no seu primeiro encontro no cume, que tivo lugar en Xenebra en 1985, Reagan sorprendeu ao presidente Mijail Gorbachov propóndolle un tratado de cooperación militar entre a Unión Soviética e os Estados Unidos para o suposto de que o noso planeta fose obxecto dunha invasión por parte dos extraterrestres. Posteriormente comprobouse que esta moción non estaba no memorándum que o goberno norteamericano lle preparara ao seu Presidente, senón que se debeu á iniciativa persoal do propio Reagan. A resposta de Gorbachov foi, así mesmo, digna dun gran mandatario: declinou comproI0 meterse aducindo que non tiña clara a posición da teoría marxista-leninista acerca da lexitimidade de cooperar cos imperialistas contra unha invasión interplanetaria. Reagan entendeu, con todo, que isto era unha desculpa de mal pagador. Así, ao regresar ao seu país contou a historia aos estudantes dunha "high school" de Maryland engadindo que, na súa valoración, marcouse un punto fronte a Gorbachov e a Unión Soviética. Cando tivo noticia do episodio, Colin Powell, xa entón deputado nacional conselleiro de seguridade, púxose feito unha furia e coidouse moitísimo de vixiar en diante a aparición de referencias aos "little green men", os "homiños verdes" invasores extraterrestres, nas intervencións públicas do Presidente. Identificou tamén a fonte da proposición xenebrina a Gorbachov: o filme de ciencia-ficción estreado en 1951 The Day the Earth Stood Still, dirixido por Robert Wise e protagonizado por Michael Rennie e Patricia Neal.

A actitude chinesa mencionada ao principio do artigo representa unha evidente negación da realidade. Reagan foi, ao que se ve, mestre na retórica precisa para substituíla pola ficción como punto de referencia para a súa política. Vexamos outra modalidade do mesmo proceso, consistente en profetizar o futuro da realidade a partir da mixtificación banalizadora do presente e a ficción do pasado. 
Fai uns vinte anos, a aparición nocturna dun cometa, semellante ao que no ano 1000 suxeriu aos monxes de Lotharingia que o Xuízo Final estaba a piques de caer, reavivou o mesmo sentimento entre os membros da seita californiana Heaven’s Gate, que en número de dezaoito homes e vinte e unha mulleres apareceron mortos no seu luxoso Rancho Santa Fe, entre os cales se atopaba o seu líder, Marshall Herff Applewhite, un dos históricos da máis marxinal da New Age, a Nova Era, que tivo no modisto Paco Rabanne un dos seus voceiros máis acreditados.

Morreron todos convencidos do seu destino mediante o expediente de inxerir salsa de mazá mesturada con fenobarbital. Eran entusiastas de Internet, rendían culto aos ovnis, e de feito crían que o cometa Ale-Bopp viña seguido dun obxecto voador non identificado que cuadriplicaba o tamaño da terra. En cintas de vídeo deixaron as súas explicacións: esperáballes un mundo mellor noutra galaxia á que os transportaría unha nave espacial. Aquí, no grupo Heaven's Gate, como tamén no grupo canadense do Templo Solar que se inmolou na fogueira dunha casa de campo de Saint Casimir, danse varias coincidencias que introducen unha interesante posta ao día no apocaliptismo mediante a irrupción dos ovnis (ou da nave Mir tan temida por Paco Rabanne).

Outra característica desta seita milenarista, cuxos membros morreron literalmente cos Nikes postos, era a súa absoluta inmersión na cultura trivial do consumismo norteamericano. Sabemos dos seus días previos ao suicidio colectivo: foron ao cinema ver A guerra das galaxias, ao zoolóxico e ao acuario de San Diego, gravaron as súas mensaxes testamentarias, comeron pizza e tamén asistiron á proxección de Segredos e mentiras (1995) de Mike Leigh. Interésame destacar precisamente esta mediación fílmica. Os testemuños dos suicidas son moi claros ao respecto: tamén lles encantaba Star Trek e series televisivas que se centran no tema da conspiración, como Expediente Xe Dark Skies. A infinita credulidade destas seitas non era moi diferente á dos miles de europeos que se botaron desesperados ao camiño no ano 1000, pero agora non eran predicadores desguedellados ou clérigos visionarios os que os seducían coas súas retóricas, senón as profecías de "tensión premilenaria" ás que deu forma Hollywood e diseminaron os medios de comunicación. Nunha sociedade na que tan poucas persoas estaban preparadas para tomar unha postura perante o ano 2000 e, pola contra, tantas eran receptivas á suxestión, as películas e as series televisivas abasteceron a un público formado por millóns de persoas de dramas apocalípticos. 
O século XX, mortal como todos e xa finalizado, foi cruelmente mortífero dende as dúas guerras mundiais, co Holocausto, Hiroshima e Nagasaki, até o terrorismo e a limpeza étnica, e un tanto mortuorio no plano filosófico ou conceptual. Nietzsche proclamou a morte de Deus en 1883. Pola súa banda, Francis Fukuyama inaugurou hai varios lustros o final da Historia, que chegaría á súa culminación grazas a un statu quo supostamente definitivo que Reagan subscribiría: a democracia liberal e a economía de mercado, aínda que Fukuyama acabaría por matizar as súas teses de entón admitindo que a Historia non morrerá definitivamente até que os avances da biotecnoloxía non consigan abolir os seres humanos como tales para que comece unha nova historia poshumana.

\section{A suplantación do real no novo século}

O que parece máis precupante é algo, se non tan radical como a morte da realidade, si polo menos próximo á súa apocalipse. No entanto, a continuación do artigo centrarase, sobre todo, no estudo da suplantación do real polos signos do real, que, como veremos, non é cousa nova, pero que sen

12 dúbida pode adquirir neste novo século o carácter dunha especie de sostida maldición milenarista.

"A forza do falso" foi, precisamente, o tema brillantemente desenvolvido por Umberto Eco na inauguración do curso académico 1994-1995 na Universidade de Boloña, onde demostra como a falsidade (e non necesariamente baixo forma de mentira, senón baixo forma de erro) foi o motor de moitos acontecementos da historia. Isto impón o manterse alerta para reescribir a "enciclopedia de cada día" como o primeiro deber da xente de cultura.

Noam Chomsky repara así no uso dos medios de comunicación para "crear consensos", para producir na poboación, mediante unha verdadeira enxeñaría propagandística, a aceptación maioritaria de algo non desexado en principio para domesticar o rabaño desconcertado. Reinold Niebuhr, líder dos intelectuais que asesoraban a John F. Kennedy, defendía xa que a racionalidade é unha condición por natureza minoritaria, mentres que a maioría da xente se guía polas emocións e os impulsos.

Así, John Brady Kiesling, conselleiro político na embaixada norteamericana en Grecia, presentou en 2003 unha soada carta de dimisión ante o entón 
xa Secretario de Estado Colin Powell, protestando que, a raíz do 11-S, estaba a producirse unha distorsión da intelixencia e unha manipulación da opinión pública norteamericana tan só equiparábel ás da guerra de Vietnam. Para Kiesling, "estamos a sementar, de maneira claramente desproporcionada, o terror e a confusión nas mentes da poboación, vinculando arbitrariamente problemas que carecen de relación entre si, como é o caso do terrorismo e Iraq".

Vimos xa, á mantenta do propio Reagan e da seita Heaven's Gate, o poder creativo das realidades do cinema, e na mente de todos están numerosos exemplos referidos á mesma facultade no caso da literatura. Non podemos esquecer, con todo, a achega da radio nesta liña de invención da realidade, para o que é obrigado lembrar o programa que Orson Welles emitiu pola CBS o 30 de outubro de 1938, o día do Halloween, esa especie de entroido ianqui propicio para as sorpresas e as bromas fantasmagóricas, sobre a novela de H. G. Wells A guerra dos mundos.

Aquí cómpre facer unha aclaración: é preciso recordar tamén a intensa actividade xuvenil de Ronald Reagan como locutor radiofónico en Deas Moines, Iowa, de onde se foi en 1937, aos 26 anos, para introducirse en Hollywood. En efecto, antes que actor, Reagan foi un exitoso locutor na emisora local da cadea $\mathrm{WHO}$, onde destacou por unha curiosa especialidade. Consistía na recreación dos partidos de béisbol xogados polos Chicago Cubs. Reagan narrábaos dende Deas Moines, xogase onde xogase o equipo, a partir dos telegramas que lle ían mandando dende o campo a medida que o xogo avanzaba. Loxicamente, a información era telegráfica e Reagan encargábase de pór os detalles, o ornatus. Houbo unha vez en que a comunicación telegráfica interrompeuse durante un certo tempo, pero o intrépido locutor non se amedrentou e nese lapso, máis que recrear o xogo, realmente inventouno coa súa retórica.

Volvendo á CBS e a Orson Welles, este emitía á mesma hora que o programa de radio máis popular do país, Chase and Sanborn Hour, do ventrílocuo Edgar Bergen. E para conseguir polo menos por unha vez captar a atención maioritaria dos radioafeccionados preparou unha actualización da novela $A$ guerra dos mundos, de H. G. Wells.

O programa comezou enmarcando o relato nun contexto de ficción, ao anunciar o locutor que a CBS, Orson Welles e o Mercury Theatre presenta- 
ban dita versión. Logo seguiu a voz do propio Orson introducindo a acción e situándoa na máis estrita contemporaneidade, o 30 de outubro de 1938. A súa voz desvaneceu entón para dar paso a un parte meteorolóxico e a unha emisión de música hispanoamericana dende un hotel de Nova York ao que os censores da CBS obrigaran a dar un nome ficticio.

E alí interrómpese a interpretación de "A cumparsita" para dar noticia de que un astrónomo observara alteracións ígneas en Marte. O que seguiu é ben coñecido: sucesivas interrupcións van incrementando o clímax cando o xornalista Carl Phillips describe, con especial ilustración auditiva dos fenómenos que enuncia, a aterraxe dun ovni, "obxecto voador non identificado", en Grover Mills, New Jersey, do que sae un extraterrestre agresivo. Comeza así unha invasión que os radioafeccionados, que non escoitaran o comezo do programa, confunden coa realidade, o que dá lugar ao pánico xeneralizado. Todo foi cuestión de contexto e montaxe. Como non ouviran a habitual introdución que enmarcaba o programa nun contexto ficticio, moitísimos cidadáns tomárono por un feito real. A actividade previa de Welles no teatro e na radio apuntaba na dirección de que lle divertía a idea de romper o marco, de confundir deliberadamente as barreiras firmes e tranquilizadoras que separan a ficción da realidade. Logo viñeron os efectos secundarios: unha riada de preitos por un valor global de 200.000\$. Non houbo mortes, pero si abortos e roturas de pernas. Un tatexo de nacemento, a quen un psicólogo acababa de curar e que recaeu por mor do susto que Welles lle propinou, demandouno para que lle pagase $2.000 \$$ e así renovar a súa terapia.

O mércores 13 de decembro de 2006 a televisión francófona belga RTBF interrompía ás 20:21 horas o seu programa semanal de xornalismo de investigación Questions à la une para emitir un telexornal de última hora coa noticia de que Flandes acababa de proclamar unilateralmente a súa independencia. En termos dramáticos, o presentador anuncia que o rei Alberto II abdicara antes de emprender o seu exilio cara a África e que, literalmente, Bélxica deixara de existir. Unha conexión en directo co palacio real de Bruxelas mostra a un grupo de exaltados independentistas flamencos axitando as súas bandeiras e dende o Atomium conéctase cun grupo de políticos que buscaran refuxio alí. A edición especial do telexornal continúa até pouco antes das 9 da noite e só entón aparece na parte inferior da pantalla dos televisores a lenda Ceci est une fiction. 
Posteriormente, unha enquisa do diario flamenco De Standar apunta que o $86 \%$ dos espectadores creron a mentira cos ollos pechados e que, mesmo aclarada a manipulación, un $6 \%$ seguiu pensando que o país se partira. Ao día seguinte, o diario francófono Le Soir titulaba "Bélxica morreu onte pola noite" e o conservador A Libre Belgique cualificaba o sucedido nos seguintes termos: "A ficción que estremece Bélxica". O Orson Welles de semellante manipulación informativa foi neste caso Philippe Dutilleul, un veterano da televisión francófona e autor do libro Bye, bye Belgium (2006) sobre o conflito entre valóns e flamencos, cuxo audaz programa foi cualificado polo primeiro ministro Guy Verhofstadt como "unha broma de mal gusto" urdida por un auténtico "irresponsable". Dutilleul deféndese argumentando que trataba de denunciar o deliberado confusionismo que practica a televisión cando sistematicamente mestura información con ficción ou coa chamada "telerrealidade". Rotundamente afirmaba: "que diferenza hai entre esta mentira e o resto das mentiras que contan os políticos cada día en televisión?”. Acaso non creron os estadounidenses que había armas de destrución masiva en Iraq?

Ao respecto, non é difícil lembrar, por caso, o bombardeo de Trípoli e Bengasi por parte dos norteamericanos ás sete da tarde (hora da costa este norteamericana) dun día de abril de 1986, que o presidente Reagan xustificou como "un acto de autodefensa contra un ataque futuro". Díxose que foi a primeira acción militar importante da historia planeada para que puidese verse por televisión na hora de máxima audiencia.

\section{Conclusión}

O poder demiúrgico da palabra como creadora, máis que reprodutora, da realidade, fortaleceuse coa escritura, ao proxectar aquel efecto dende o momento da súa primeira enunciación a través do tempo e o espazo, pero tamén se viu incrementado coa segunda revolución tecnolóxica da imprenta e volve facelo, de forma redobrada, cos avances da nosa era da comunicación audiovisual dixitalizada e a súa propia retórica.

Os medios audiovisuais teñen hoxe nas súas mans, con redobrada intensidade, a capacidade de crear realidades: guerras e paces, heroes e viláns, presenzas e ausencias. Por iso non é do todo desatinada aquela pregunta formulada hai anos por algúns pensadores: vostedes cren realmente que os astronautas norteamericanos chegaron á lúa? 
Sendo como é este asunto tan antigo como a Humanidade, adquire no entanto novas e preocupantes dimensións na era posmoderna que vivimos, coa súa invención da chamada realidade virtual. Cabe preguntarse se a tecnoloxía audiovisual e as novas plataformas comunicativas poderán destruír dunha vez por todas a nosa facultade de discernir entre verdade e mentira, entre a historia e a fábula.

Da incidencia de todo iso no noso mundo actual dá fe, precisamente, a irrupción da posverdade.

Darío Villanueva Prieto

Universidade de Santiago de Compostela

\section{Bibliografía}

Cannon, Lou. 1991. President Reagan: The Role Of A Lifetime. New York: Simon and Schuster.

Dutilleul, Philippe. 2006. Bye, bye, Belgium. Belgique: Éditions Labor.

Llamazares, Julio. 22 de abril de 2017. "La posmentira", en El País, https://elpais.com/elpais/2017/04/21/opinion/1492794405_409312.html [Consulta: $10 / 03 / 2019]$.

Morris, Edmund. 1979. The Rise of Theodore Roosevelt. New York: Coward, McCann \& Geoghegan.

Morris, Edmund. 1999. Dutch: A Memoir of Ronald Reagan. United States: Random House.

Orwell, George. 1949. Nineteen Eighty-Four. Reino Unido: Secker \& Warburg.

Verdú, Luís. 2003. El prisionero de las 21:30. Madrid: Editorial Debate. 